\title{
sciendo
}

\author{
Current Issues in Pharmacy and Medical Sciences
}

Formerly ANNALES UNIVERSITATIS MARIAE CURIE-SKIODOWSKA, SECTIO DDD, PHARMACIA

journal homepage: http://www.curipms.umlub.pl/

\section{Urinary iodine as an important indicator for preeclampsia: a Polish perspective}

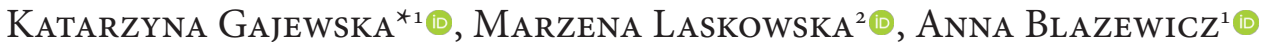

${ }^{1}$ Chair of Chemistry, Department of Analytical Chemistry, Medical University of Lublin, Poland

${ }^{2}$ Chair and Department of Obstetrics and Perinatology, Medical University of Lublin, Poland

\begin{tabular}{l}
\hline ARTICLE INFO \\
\hline Received 25 April 2021 \\
Accepted 19 July 2021
\end{tabular}

\section{Keywords:}

iodine,

preeclampsia,

pregnancy.

\begin{abstract}
Preeclampsia (PE) is one of the leading causes of perinatal and maternal morbidity. Although subclinical hypothyroidism in pregnancy is one of the established risk factors for PE, the link between iodine deficiency and PE is not fully understood. The aim of our study was to assess urinary iodine concentration (UIC), serum thyroid-stimulating hormone (TSH), free triiodothyronine (fT3), and free thyroxine (fT4) levels in Polish women with $\mathrm{PE}$ (PE group, $\mathrm{n}=78$ ) compared with healthy non-pregnant women (CNP group, $n=30$ ), and healthy pregnant women (CP group, $n=46$ ). The UIC was determined by inductively coupled plasma mass spectrometry (ICP-MS). Both the mean UIC of $144.6 \pm 36.4 \mu \mathrm{g} / \mathrm{L}$ in the CP group and the mean of $125.8 \pm 33.6 \mu \mathrm{g} / \mathrm{L}$ in the PE group, respectively, were lower compared to non-pregnant women $(149.8 \pm 28.8 \mu \mathrm{g} / \mathrm{L})$, and the difference between the PE and CNP groups was statistically significant. TSH values were the highest in the PE group, while the lowest average level was for the CNP group. The fT3 and fT4 values in the PE group were significantly lower compared to the CNP and CP groups. Despite iodine supplementation during pregnancy, the UIC was lower compared to non-pregnant women, while in women with PE it was at a significantly lower level. To reduce the incidence of possible health complications, proper iodine supplementation and monitoring of the UIC is recommended for pregnant women suffering from PE or at risk of developing PE.
\end{abstract}

\section{INTRODUCTION}

Preeclampsia (PE) is one of the leading causes of perinatal and maternal morbidity, which complicates $2-8 \%$ of pregnancies worldwide. PE is diagnosed after the $20^{\text {th }}$ week of gestation in the presence of hypertension (blood pressure $\geq 140 / 90 \mathrm{mmHg}$ ) and proteinuria $(>0.3 \mathrm{~g}$ in a 24-hour collection of urine) [1]. It can lead to preterm delivery, foetal growth restriction (FGR), multi-organ system dysfunction and maternal or foetal death [2]. The pathophysiology of this disorder remains poorly understood, which limits therapeutic intervention [3]. The possible causes of PE are abnormalities in the development of placental vascular tissue during the first trimester and oxidative stress that arises from factors released by the placenta $[4,5]$. Although the exact cause remains uncertain, the risk factors of $\mathrm{PE}$ are well known $[6,7]$. The most important factors include elevated body mass index, obesity, chronic hypertension, prediabetes or diabetes, and the presence of PE during a previous pregnancy or in the

\footnotetext{
* Corresponding author

e-mail: katarzyna.krupa@umlub.pl
}

family history. In addition, first pregnancy, multiple pregnancies, maternal age (younger than 20 or older than 35 years), and African ancestry are associated with PE $[7,8]$. Subclinical hypothyroidism in pregnancy is one of the established risk factors for PE, however, the link between iodine deficiency and PE remains mostly unknown [9].

Iodine deficiency is one of the major causes of thyroid dysfunction and affects approximately two billion people worldwide. It has recently been found that different groups of the population have mild to moderate iodine deficiency, especially children and pregnant women [10]. Some studies suggest that oxidative stress may be a contributing factor to PE and that iodine, as one of the most potent exogenous antioxidants, may reduce the risk of this disorder $[11,12]$. Iodine deficiency is associated with oxidant imbalance and endothelial dysfunction, which is one of the mechanisms associated with increased risk of PE [9]. Iodine is also one of the most important microelements which play a crucial role in human physiology [13]. It is essential for the production of maternal and foetal thyroid hormones and its deficiency 
may cause significant clinical symptoms [14]. Adequate levels of thyroid hormones are especially important for cell migration, myelination, differentiation and maturation of the foetal brain $[15,16]$. Severe iodine deficiency is especially dangerous in pregnancy as it affects foetal growth and development and can cause congenital hypothyroidism resulting in cretinism and impaired neurodevelopment [16]. Recommendations by the WHO set the minimal urinary iodine concentration (UIC) as $100 \mu \mathrm{g} / \mathrm{L}$. This recommended dose corresponds to a daily intake of $150 \mu \mathrm{g}$ iodine. The latest recommended amount for adults is $150 \mu \mathrm{g} /$ day and $200 \mu \mathrm{g}$ for pregnant or lactating women $[17,18]$.

There are many controversial results in the literature regarding the relationship between UIC and the risk of PE. Some of the studies reported lower iodine levels in women with PE compared to healthy pregnant women [19-21], while other studies show opposite results $[9,22]$. Iodine deficiency is very common among pregnant women in many European countries, as well as in the USA [23], therefore it is necessary to verify the possible relationship between the iodine level and the risk of PE. Within this context, the aim of this study was to compare the UIC in preeclamptic, healthy pregnant, and healthy non-pregnant women. Furthermore, we aimed to assess serum thyroid-stimulating hormone (TSH), free triiodothyronine (fT3), and free thyroxine (fT4) levels within the same groups.

\section{MATERIALS AND METHODS}

\section{Study population}

This study was approved by the ethics committee of the Medical University of Lublin (No KE-0254/251/2016). Informed consent was obtained from all patients before blood and urine sampling. Samples were collected from pregnant women admitted to Independent Public Clinical Hospital No. 4 in Lublin during either routine testing or their stay at the hospital. Patients were divided into three groups: control non-pregnant (CNP group, $\mathrm{n}=30$ ), control pregnant (CP group, $\mathrm{n}=46$ ) and women with PE (PE group, $\mathrm{n}=78$ ). The inclusion criteria for control groups were as follows: healthy and normotensive women with the absence of proteinuria. The PE group was classified based on the definition of the American College of Obstetrics and Gynaecologists [24]. Patients with diabetes, hypertension, thyroid diseases, or those taking thyroid medications were excluded from the study. Participants supplementing iodine as recommended for pregnant women, were not excluded from the study.

\section{Collection of the samples}

Urine samples were collected directly into plastic urine collection containers. The collected urine samples were then aliquoted and stored frozen at $-25^{\circ} \mathrm{C}$ until analysis. For TSH, fT3, and fT4 levels, fasting venous blood samples $(5 \mathrm{~mL})$ were drawn in sterile vacutainers and were centrifuged at $3.000 \mathrm{rpm}$ for $15 \mathrm{~min}$ to extract the serum.

\section{Biochemical analysis}

Serum measurements of TSH, fT3 and fT 4 were performed by an accredited diagnostic lab (ALAB Medical Analysis Laboratory, 8 Jaczewskiego Street, Lublin).

\section{Iodine determination in urine samples}

The UIC was measured by inductively coupled plasmamass spectrometry (ICP-MS, Thermo Fisher Scientific, Bremen, Germany), according to the method developed by the Centres for Disease Control and Prevention (CDC) (25). The ICP-MS instrument operational parameters were as follows: RF power $(1550 \mathrm{~W})$; plasma gas flow $(14 \mathrm{~L} /$ $\mathrm{min})$; auxiliary gas flow $(0.8 \mathrm{~L} / \mathrm{min})$; nebulizer flow rate $(0.95 \mathrm{~L} / \mathrm{min})$. The iodine $\left({ }^{127} \mathrm{I}\right)$ isotope was monitored for analytical determination, and the tellurium $\left({ }^{125} \mathrm{Te}\right)$ isotope was monitored as an internal standard.

The following diluent was used to prepare the solutions: $1.0 \%(\mathrm{v} / \mathrm{v})$ tetramethylammonium hydroxide - TMAH $25 \%$ $\mathrm{w} / \mathrm{w}, 0.01 \%$ Triton $^{\mathrm{TM}} \mathrm{X}-100$ and $10 \mu \mathrm{g} / \mathrm{L}$ Te (HPLC grade, Sigma Aldrich, St. Louis, MO, USA). An aqueous solution of $1 \%$ TMAH and $0.1 \%$ Triton X-100 was used for ICP-MS rinsing. The urine samples were diluted 10 -fold with $1 \%$ (v/v) TMAH containing tellurium for internal standardization. The base urine used in this method was a pool of urine samples from several participants. It was combined with intermediate working standards during the dilution process just prior to analysis. The calibration standard solutions were prepared by adequate dilution of the iodine standard, and the calibration curve was obtained with six solutions of iodine concentrations within the $25-1000 \mu \mathrm{g} / \mathrm{L}$ range. The internal standard solution was added to all samples, as well as the standard solutions to obtain a $10 \mu \mathrm{g} / \mathrm{L}$ final concentration.

For validation and analytical quality control purposes, the certified reference materials (CRMs): Trace Elements Urine, L1 and L2 (Seronorm ${ }^{\mathrm{TM}}$, Sero, Billingstad, Norway) were used and were analysed under the same conditions as the samples. All measurements were conducted in triplicate.

\section{Statistical analyses}

Statistical analyses were performed using TIBCO Software Inc. (2017) Statistica, v.13.0.0.0 (TIBCO, Tulsa, USA). Descriptive statistics were produced for the overall sample population, as well as for the groups: CNP, CP, PE. The Shapiro-Wilk test indicated that the variables were not normally distributed (Table 1), therefore, the non-parametric Kruskal-Wallis ANOVA test was applied for the comparison of variables. The homogeneity of variance was checked via Levene's test.

Table 1. The p-value from the Shapiro-Wilk test for normality in the groups

\begin{tabular}{|l|c|c|c|}
\hline \multicolumn{1}{|c|}{ Group/variable } & CNP & CP & PE \\
\hline UIC $(\mu \mathrm{g} / \mathrm{L})$ & 0.03 & 0.08 & 0.08 \\
\hline TSH $(\mathrm{mU} / \mathrm{L})$ & 0.04 & 0.04 & 0.00 \\
\hline $\mathrm{fT} 3(\mathrm{ng} / \mathrm{L})$ & 0.13 & 0.13 & 0.00 \\
\hline $\mathrm{fT} 4(\mathrm{ng} / \mathrm{L})$ & 0.04 & 0.04 & 0.00 \\
\hline
\end{tabular}

Since the parametric tests could not be used, Dunn's post-hoc tests were performed to check which specific groups' averages were different from each other. Bonferroni correction was applied to keep the first type error at $\alpha=0.05$. A logistic regression analysis with a continuous dependent variable was used to evaluate the association between the UIC and PE. The quality of the model fit was checked with 
the log-rank test to assess whether the model with the UIC variable improves the model built only with the intercept. The significance of the coefficient with the UIC variable in the model was tested with Wald's test. The goodness of the model's fit was tested with the Lomershow-Hosmer test (where a p-value above 0.05 indicates that the model fits the data well). The absence of excessive scatter was assessed based on the scaled chi-square coefficient (a value of the coefficient around 1 indicates that the model does not have excessive scatter). Based on the ROC curve, the classification possibilities of the model were examined.

\section{RESULTS}

\section{Descriptive statistics for the overall studied population}

A detailed characterisation of the studied population is presented in Table 2. As the variables were not normally distributed, nonparametric tests were used for the comparison.

Table 2. Patient characteristics

\begin{tabular}{|c|c|c|c|c|c|c|}
\hline & $\begin{array}{l}\underset{\mathbb{N}}{\mathbb{N}} \\
\sum\end{array}$ & 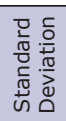 & $\begin{array}{l}\frac{c}{0} \\
\frac{\pi}{0} \\
\sum \\
\Sigma\end{array}$ & $\begin{array}{l}\frac{E}{J} \\
\stackrel{\underline{E}}{E} \\
\dot{\Sigma}\end{array}$ & $\begin{array}{l}\frac{E}{J} \\
\frac{E}{x} \\
\sum^{\pi}\end{array}$ & 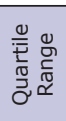 \\
\hline \multicolumn{7}{|c|}{ All participants $n=154$} \\
\hline Age (years) & 27.8 & 4.6 & 28.0 & 18.0 & 45.0 & 5.0 \\
\hline UIC $(\mu \mathrm{g} / \mathrm{L})$ & 136.1 & 35.1 & 135.7 & 51.7 & 245.6 & 38.4 \\
\hline TSH (mU/L) & 1.6 & 0.6 & 1.7 & 0.3 & 2.5 & 1.0 \\
\hline fT3 (ng/L) & 2.4 & 0.9 & 2.3 & 1.0 & 4.6 & 1.6 \\
\hline fT4 (ng/L) & 14.7 & 2.7 & 14.1 & 10.3 & 20.4 & 4.3 \\
\hline \multicolumn{7}{|c|}{ Control Non-pregnant (CNP) $n=30$} \\
\hline Age (years) & 27.2 & 7.5 & 26.0 & 18.0 & 45.0 & 12.0 \\
\hline UIC $(\mu \mathrm{g} / \mathrm{L})$ & 149.8 & 28.8 & 147.9 & 82.4 & 245.6 & 27.8 \\
\hline TSH (mU/L) & 1.2 & 0.5 & 1.1 & 0.4 & 2.1 & 0.8 \\
\hline fT3 (ng/L) & 2.7 & 0.9 & 2.6 & 1.2 & 4.6 & 1.5 \\
\hline fT4 (ng/L) & 16.2 & 2.9 & 16.5 & 11.6 & 20.4 & 5.0 \\
\hline \multicolumn{7}{|c|}{ Control Pregnant $(\mathrm{CP}) n=46$} \\
\hline Age (years) & 29.2 & 3.7 & 29.0 & 21.0 & 38.0 & 4.0 \\
\hline Gestational age (weeks) & 25.5 & 10.2 & 27.5 & 10.0 & 40.0 & 18.0 \\
\hline UIC $(\mu \mathrm{g} / \mathrm{L})$ & 144.6 & 36.4 & 141.2 & 65.1 & 243.0 & 33.5 \\
\hline TSH (mU/L) & 1.5 & 0.6 & 1.5 & 0.3 & 2.4 & 1.0 \\
\hline fT3 (ng/L) & 2.5 & 1.0 & 2.5 & 1.0 & 4.1 & 1.5 \\
\hline fT4 (ng/L) & 15.2 & 2.3 & 14.8 & 10.3 & 19.5 & 2.8 \\
\hline \multicolumn{7}{|c|}{ Preeclampsia (PE) $n=78$} \\
\hline Age (years) & 27.3 & 3.3 & 28.0 & 20.0 & 41.0 & 5.0 \\
\hline Gestational age (weeks) & 34.3 & 3.7 & 35.0 & 22.0 & 39.0 & 2.0 \\
\hline UIC $(\mu \mathrm{g} / \mathrm{L})$ & 125.8 & 33.6 & 124.0 & 51.7 & 217.4 & 40.2 \\
\hline $\mathrm{TSH}(\mathrm{mU} / \mathrm{L})$ & 1.8 & 0.5 & 1.9 & 0.3 & 2.5 & 0.7 \\
\hline fT3 (ng/L) & 2.1 & 0.9 & 2.1 & 1.0 & 3.9 & 1.8 \\
\hline fT4 (ng/L) & 14.0 & 2.5 & 13.2 & 10.6 & 19.8 & 2.6 \\
\hline \multicolumn{7}{|c|}{ Iodine supplementation } \\
\hline Group & \multicolumn{2}{|c|}{ Yes } & $\%$ & \multicolumn{2}{|c|}{ No } & $\%$ \\
\hline All participants $(n=154)$ & \multicolumn{2}{|c|}{$n=103$} & 67 & \multicolumn{2}{|c|}{$n=49$} & 33 \\
\hline $\operatorname{CNP}(n=30)$ & \multicolumn{2}{|c|}{$n=0$} & 0 & \multicolumn{2}{|c|}{$\mathrm{n}=30$} & 100 \\
\hline $\mathrm{CP}(n=46)$ & \multicolumn{2}{|c|}{$n=39$} & 85 & \multicolumn{2}{|c|}{$n=7$} & 15 \\
\hline $\operatorname{PE}(n=78)$ & \multicolumn{2}{|c|}{$n=64$} & 82 & \multicolumn{2}{|c|}{$n=12$} & 18 \\
\hline
\end{tabular}

The mean age of all patients was $27.8 \pm 4.6$ years. The age of the CNP and PE patients was similar (27.2 \pm 7.5 vs $27.3 \pm 3.3$, respectively), while the $\mathrm{CP}$ patients were slightly older $(29.2 \pm 3.7)$. The gestational age in the PE group was significantly longer than in the CP group (34.3 \pm 3.7 vs $25.5 \pm 10.2$ ). $85 \%$ of the CP group and $82 \%$ of the PE group declared iodine supplementation in accordance with the recommendations of the Polish Gynecological Society for pregnant women [26]. Patients took mineral/ vitamin preparations dedicated to pregnant women (which contained iodine in the form of potassium iodide) at the level of 150-200 $\mu \mathrm{g} / \mathrm{day}$, while none of the CNP group supplemented iodine.

\section{The Kruskal-Wallis ANOVA test results of the comparison of three groups}

The Kruskal-Wallis ANOVA test results are presented in Table 3. There were statistically significant differences between the mean ranks in the groups for each variable.

Table 3. The Kruskal-Wallis ANOVA test results

\begin{tabular}{|l|c|c|}
\hline \multicolumn{1}{|c|}{ Variable } & $x^{2}$ & $p$-value \\
\hline UIC $(\mu \mathrm{g} / \mathrm{L})$ & 16.92 & 0.0002 \\
\hline TSH $(\mathrm{mU} / \mathrm{L})$ & 25.02 & 0.0000 \\
\hline fT3 $(\mathrm{ng} / \mathrm{L})$ & 11.18 & 0.0037 \\
\hline fT4 $(\mathrm{ng} / \mathrm{L})$ & 19.99 & 0.0000 \\
\hline
\end{tabular}

Dunn's post-hoc tests with the Bonferroni correction were performed to check which group's mean rank differ from each other. The test results are presented in Table 4. There were significant differences in the UIC between the PE group and the other groups. Moreover, there was no significant difference between the CNP and CP groups. Additionally, all groups have significantly different mean values for TSH levels. The fT3 and fT4 values in the PE group compared to the CNP and CP groups were significantly different. There were no significant differences between the CNP and CP groups.

Table 4. Dunn's post-hoc test results for the UIC, TSH, fT3 and fT4 variables

\begin{tabular}{|c|c|c|c|}
\hline Group & CNP & $\mathrm{CP}$ & PE \\
\hline \multicolumn{4}{|c|}{ UIC ( $\mu \mathrm{g} / \mathrm{L})$} \\
\hline CNP & - & 0.855063 & $0.000682 *$ \\
\hline $\mathrm{CP}$ & 0.855063 & - & $0.010819 *$ \\
\hline PE & $0.000682 *$ & $0.010819 *$ & - \\
\hline \multicolumn{4}{|c|}{$\mathrm{TSH}(\mathrm{mU} / \mathrm{L})$} \\
\hline CNP & - & $0.034245 *$ & $0.000003 *$ \\
\hline $\mathrm{CP}$ & $0.034245^{*}$ & - & $0.039880 *$ \\
\hline PE & $0.000003 *$ & $0.039880 *$ & - \\
\hline \multicolumn{4}{|c|}{ fT3(ng/L) } \\
\hline CNP & - & 1.000000 & $0.009697 *$ \\
\hline $\mathrm{CP}$ & 1.000000 & - & $0.044426^{*}$ \\
\hline PE & $0.009697 *$ & $0.044426 *$ & - \\
\hline \multicolumn{4}{|c|}{ fT4 (ng/L) } \\
\hline CNP & - & 0.697102 & $0.000174 *$ \\
\hline $\mathrm{CP}$ & 0.697102 & - & $0.005074 *$ \\
\hline PE & $0.000174 *$ & $0.005074 *$ & - \\
\hline
\end{tabular}


The Kruskal-Wallis ANOVA test results for the UIC, TSH, fT3 and fT4 values are presented in Figure 1. The UIC values in the PE group were lower than in the CNP and CP groups. TSH values were the highest in the PE group, while the lowest average level was observed for the CNP group. The fT3 and fT4 values in the PE group were significantly lower compared to the CNP and CP groups.

A.

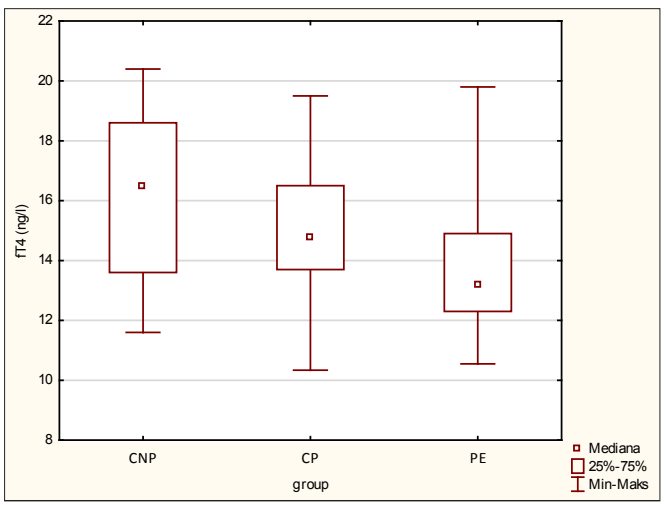

B.

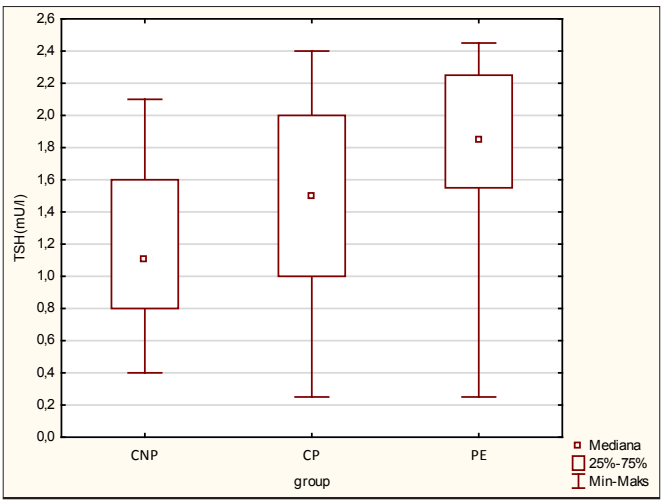

C.

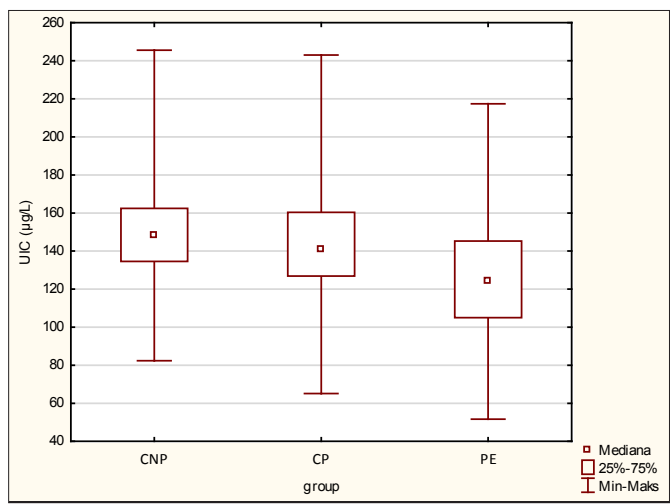

D.

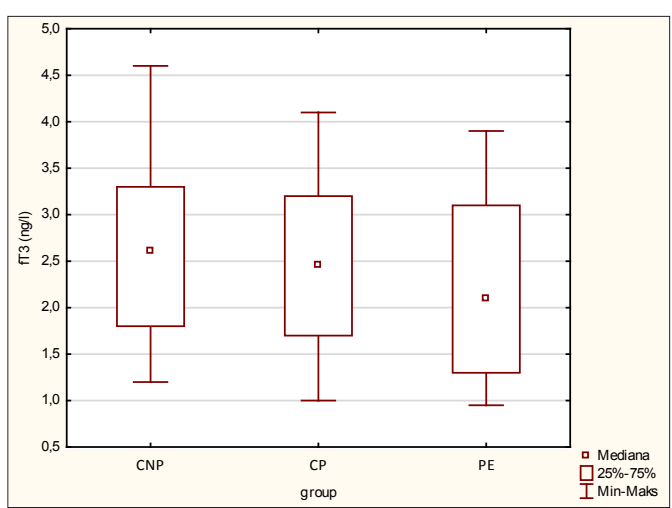

Values are presented as medians with interquartile ranges (IQR). Min-max are the minimum and maximum recorded values

Figure 1. The Kruskal-Wallis ANOVA test results for: A. UIC; B. TSH; C. fT3; D. fT4 values

\section{Logistic regression analyses of the relationship between UIC and the presence of PE}

A logistic regression model was built in which a variable classifying the state into one of the two groups (PE and $\mathrm{CP})$ was selected as the dependent variable. Here, UIC was selected as the independent variable. Application of the log-rank test ( $\mathrm{p}$-value $=0.004)$ indicated that the UIC variable significantly improved the model based only on the intercept. The p-value in the Lomershow-Hosmer test was 0.15 , which reveals that the model fits the data well. In addition, the scaled chi-square value is 1.01 , which indicates that there is no excessive scatter.

Table 5. Logistic regression analysis results

\begin{tabular}{|c|c|c|c|c|c|c|c|}
\hline & $\begin{array}{l}\frac{5}{0} \\
\stackrel{0}{0} \\
\frac{0}{\pi} \\
\frac{10}{4}\end{array}$ & 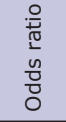 & 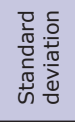 & $\begin{array}{l}\frac{1}{\pi} \\
\omega \\
\frac{0}{\pi} \\
3\end{array}$ & 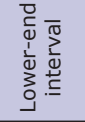 & 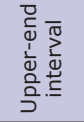 & $\begin{array}{l}\frac{0}{3} \\
\frac{3}{\pi} \\
\vdots \\
\vdots\end{array}$ \\
\hline Intercept & 2.66 & & 0.81 & 10.74 & 1.06 & 4.25 & 0.001 \\
\hline UIC $(\mu \mathrm{g} / \mathrm{L})$ & -0.015 & 0.98 & 0.006 & 7.48 & -0.027 & -0.005 & 0.006 \\
\hline
\end{tabular}

The obtained odds ratio shows that with an individual increase in the UIC variable, the probability of the patient being in the PE group decreases by $2 \%$. With the difference of 32 units between the mean values of the groups, this observation is significant.

\section{DISCUSSION}

Our study demonstrated a prevalence of maternal iodine with a mean UIC of $144.6 \pm 36.4 \mu \mathrm{g} / \mathrm{L}$ in the CP group and $125.8 \pm 33.6 \mu \mathrm{g} / \mathrm{L}$ in the PE group. These values were lower compared to the CNP group $(149.8 \pm 28.8 \mu \mathrm{g} / \mathrm{L})$. The difference between the PE and CNP group was statistically significant. Most pregnant women (both in the CP and PE groups) supplemented iodine with pregnancy vitamins at an average level of 150-200 $\mu \mathrm{g}$ per day. Despite this supplementation, the UIC was at a similar or lower level (approximately $67 \%$ of all studied patients, including $88 \%$ of all of the pregnant women, had a UIC below $150 \mu \mathrm{g} / \mathrm{L}$ ). This observation is caused by increased production of thyroid hormones, the passage of iodine across the blood-placenta barrier, and an increase in renal clearance [27]. Pregnancy induces several major changes in the physiology of the thyroid gland. Starting in early pregnancy, T4 production increases by approximately $50 \%$, circulating thyroxinebinding globulin (TBG) increases 1.5-fold, and the levels of T3 and T4 are enhanced [28]. Moreover, during the first trimester, the thyroid is also stimulated by the alpha subunit of human chorionic gonadotropin (hCG), which binds to and activates the TSH receptor. All these processes contribute to the increased demand for thyroid hormones and adequate iodine availability [29].

The upsurge in demand for iodine during pregnancy is also associated with an increase in the maternal glomerular filtration rate wherein Iodine is passively excreted, which causes additional losses of ingested iodine. The placenta and foetus also consume iodine and maternal thyroid hormone. Pessah-Pollack et al. [30] showed that pregnant women are at an increased risk for iodine deficiency. Their data reveals 
that the UIC of the pregnant women who supplemented iodine at a dose of $150 \mu \mathrm{g}$ of potassium iodide daily $(\mathrm{n}=182)$ was $169.8 \mu \mathrm{g} / \mathrm{L}$ - which was significantly higher than the group without supplementation $(128.4 \mu \mathrm{g} / \mathrm{L}, \mathrm{p}<0.01$, $\mathrm{n}=183$ ). Furthermore, the results of that study indicated that over $50 \%$ of all women were exposed to iodine deficiency during pregnancy, and more than $20 \%$ of all women who supplemented iodine were still at risk. Bath et al. [31] contribute research that British women are characterised by mild to moderate iodine deficiency (median UIC was $56.8 \mu \mathrm{g} / \mathrm{L}$ ). Moreover, their work show that only a very small number of patients supplemented iodine during pregnancy (3\%).

In the study by Gulaboglu et al. [19], the level of urinary iodine of women with severe PE was $4.25 \pm 2.7 \mu \mathrm{g} / \mathrm{dL}-$ less than $20.89 \pm 6.4 \mu \mathrm{g} / \mathrm{dL}$ of the urinary iodine of healthy pregnant women $(\mathrm{p}<0.001)$. There was no difference in thyroid hormone levels (T4, TSH, fT4). However, there was a significant difference in the $\mathrm{T} 3$ levels between women with severe PE $(1.86 \pm 0.4 \mu \mathrm{g} / \mathrm{dL})$ and healthy pregnant women $(1.45 \pm 0.3 \mu \mathrm{g} / \mathrm{dL} ; \mathrm{p}<0.001)$, and in the fT3 levels $(2.77 \pm 0.4 \mu \mathrm{g} / \mathrm{mL}$ in the PE group vs $2.41 \pm 0.5 \mu \mathrm{g} / \mathrm{dL}$ in the control group; $\mathrm{p}<0.01)$. In our study, the TSH values were the highest in the PE group, while the lowest average level was observed in the CNP group. Of note, the fT3 and fT4 values in the PE group were significantly lower compared to the CNP and CP groups. Sattar et al. [32] also saw statistically insignificant differences in the levels of TSH, fT3 and fT4 in the PE group compared to the healthy control group; however, their study was limited by it being a very small study group (PE group - 17; control group - 16). Muraleedharan et al. [33] found that TSH was significantly higher in patients with $\mathrm{PE}(3.76 \pm 1.55 \mathrm{mIU} / \mathrm{L})$ than in healthy controls $(2.30 \pm 0.94 \mathrm{mIU} / \mathrm{L})$. Mean FT3 in the PE group was $2.12 \pm 0.55 \mu \mathrm{g} / \mathrm{ml}$ and was $2.43 \pm 0.47 \mu \mathrm{g} / \mathrm{ml}$ in the control group. FT4 in the PE group was $1.16 \pm 0.24 \mathrm{ng} / \mathrm{dL}$ and was $1.33 \pm 0.27 \mathrm{ng} / \mathrm{dL}$ in controls; these data are suggestive of hypothyroidism. In the study by Khanam and Ilias [34], the mean $( \pm \mathrm{SD}) \mathrm{TSH}$ of the study group and control group was $4.14 \pm 2.24 \mathrm{mIU} / \mathrm{L}$ and $2.75 \pm 1.73 \mathrm{mIU} / \mathrm{L}$, respectively. There was a highly significant difference between the two groups $(p=0.0007)$, whilst there were no significant differences between the two groups in T3 and T4 levels (1.95 \pm 0.64 $\mathrm{nmol} / \mathrm{L}$ and $1.98 \pm 0.57 \mathrm{nmol} / \mathrm{L}$ and $128.38 \pm 33.43 \mathrm{nmol} / \mathrm{L}$ vs $126.37 \pm 34.70 \mathrm{nmol} / \mathrm{L}$, respectively; $\mathrm{p}>0.05$ ).

A study by Reische et al. [22], however, showed no significant difference in iodine levels (case mean $=26.04 \mathrm{ng} /$ $\mathrm{mL}$, control mean $=27.88 \mathrm{ng} / \mathrm{mL}, \mathrm{p}=0.995$ ) between preeclamptic and healthy women. There was also no significant difference in the TSH levels between compared groups (case mean $=1.30 \mathrm{mIU} / \mathrm{L}$, control mean $=1.24 \mathrm{mIU} / \mathrm{L}$, $\mathrm{p}=0.896$ ). Furthermore, Gargari et al. [35] did not find any statistically significant difference between maternal iodine deficiency and maternal complications of the pregnancy such as PE, gestational diabetes mellitus, premature rupture of membrane or bleeding. The results differed in the study of Yang et al. [36] that aimed to determine the effects of UIC and thyroid diseases on adverse pregnancy outcomes and the risk of various disorders like PE. Their prospective study was conducted on a large number of patients (2347 pregnant women) and their outcomes were compared between different UIC and thyroid function groups. Herein, pregnant women with a UIC between 150 and $249 \mu \mathrm{g} / \mathrm{L}$ had lower incidences of PE (adjusted odds ratio (OR) $0.12,95 \%$ CI: 0.01-0.87). In some studies, maternal hyperthyroidism was associated with an increased risk of hypertensive disorders, which may induce PE [37,38].

All the results presented above highlight a controversial association between the UIC, TSH, fT3 and fT4 levels and PE; and most studies point to iodine deficiency in the population. In our opinion, this problem is important, and attempts should be made to improve the current situation. In Poland, there is a strategy of iodine prophylaxis that requires iodised table salt and supplements for infant's iodization. Moreover, it recommends an additional dose of iodine during pregnancy/breastfeeding and increasing the consumption of natural iodine carriers, such as sea fish, milk, or mineral waters with an iodide concentration of $100-200 \mu \mathrm{g} / \mathrm{L}$ $[39,40]$. Despite these actions, most Polish pregnant women suffer from iodine deficiency [41]. Thus, it can be concluded that the effectiveness of iodine prophylaxis is not satisfactory. Based on the WHO guidelines, where UIC below 150 $\mu \mathrm{g} / \mathrm{L}$ can pose a risk of iodine deficiency, approximately $67 \%$ of all studied patients, including $88 \%$ of all pregnant women, were at risk for mild, moderate or severe iodine deficiency, which indicates insufficient iodine intake in pregnancy, despite additional supplementation. This is particularly dangerous for women at risk of developing PE.

\section{CONCLUSIONS}

An increase in serum TSH levels with a concomitant decrease in thyroid hormones indicates hypothyroidism, but is not synonymous with iodine deficiency. To determine whether a patient is iodine deficient, a urine test for iodine should be performed. Our studies suggest that such tests should be performed routinely, especially in patients with PE where not only significantly lower mean UIC was found, but also hormonal alterations (i.e. the highest values of TSH, and the lowest fT3 and fT4 values) in the PE group compared with the healthy controls.

Despite iodine supplementation during pregnancy, the UIC was lower compared to non-pregnant women, while in women with PE it was at a significantly lower level. To reduce the incidence of possible health complications, proper iodine supplementation and monitoring of the UIC is recommended for pregnant women suffering from PE or at risk of developing PE.

\section{FUNDING}

Financial support of the studies: DS 53/Anna Błażewicz, Medical University of Lublin, Poland.

\section{ACKNOWLEDGMENTS}

The authors would like to express their sincere gratitude to all the women who participated in the study and to the research support of Agostinho Almeida from LAQV/REQUIMTE, Department of Chemical Sciences, Faculty of Pharmacy, University of Porto, as well as Edgar Pinto from the Department of Environmental Health, School of Health, Porto, Portugal. 


\section{CONFLICT OF INTEREST}

The authors declare no conflict of interest.

\section{ORCID iDs}

Katarzyna Gajewska (Dhttps://orcid.org/0000-0003-4930-4147 Marzena Laskowska (Dhttps://orcid.org/0000-0003-2602-4249 Anna Błażewicz (1)https://orcid.org/0000-0001-9758-5831

\section{REFERNCES}

1. Amaral LM, Wallace K, Owens M, Lamarca B. Pathophysiology and current clinical management of preeclampsia. Curr Hypertens Rep. 2017;19(61):19-21.

2. The American College of Obstetricians and Gynecologists. ACOG Practice Bulletin number 202: Gestational hypertension and preeclampsia. Obstet Gynecol. 2019;133(1):el-e325.

3. Burton GJ, Redman CW, Roberts JM, Moffett A. Pre-eclampsia : pathophysiology and clinical implications. BMJ. 2019;366:12381.

4. Aouache R, Biquard L, Vaiman D, Miralles F. Oxidative stress in preeclampsia and placental diseases. Int J Mol Sci. 2018;19:1496.

5. Bustan-Nahumson M, Bornstein S, Feldstein O, Levy M, Schreiber L, Bar J, et al. Preeclampsia in different maternal age groups - is there an association with pregnancy outcomes and placental pathology? Reprod Sci. 2020;27:1879-87.

6. Armaly Z, Jadaon JE, Jabbour A, Abassi ZA. Preeclampsia : Novel mechanisms and potential therapeutic approaches. Front Physiol. 2018;9:1-15.

7. English FA, Kenny LC, Mccarthy FP. Risk factors and effective management of preeclampsia. Integr Blood Press Control. 2015;8:7-12.

8. Lisonkova S, Joseph KS. Incidence of preeclampsia: Risk factors and outcomes associated with early - versus late-onset disease. Am J Obstet Gynecol. 2013;209(6):544.e1-544.e12.

9. Businge CB, Madini N, Longo-mbenza B, Kenge A P. Insufficient iodine nutrition status and the risk of pre-eclampsia : A protocol for systematic review and meta-analysis. BMJ Open. 2019;9 (e025573).

10. Businge CB, Longo-Mbenza B, Adeniyi OV, Babeki VN, Kaboka AK, Muaka MM, et al. Iodine deficiency in pregnancy as a predictor of sub-clinical hypothyroidism, preeclampsia and future cardiovascular disease. Asian J Clin Nutr. 2017;9(3):118-23.

11. Cuellar-Rufino S, Navarro-Meza M, Garcia-Solis P, Xochihua-Rosas I, Arroyo-Helguera O. Iodine levels are associated with oxidative stress and antioxidant status in pregnant women with hypertensive disease. Nutr Hosp. 2017;34(3):661-6.

12. Aceves C, Anguiano B, Delgado G. The extrathyronine actions of Iodine as antioxidant, apoptotic and differentiation factor in various tissues. Thyroid. 2013;23(8):938-46.

13. Lazarus JH. Iodine Status in Europe in 2014. Eur Thyroid J. 2014;3: 3-6.

14. Harding K, Peña-rosas J, Webster A, Yap C, Payne B, Ota E, et al. Iodine supplementation for women during the preconception, pregnancy and postpartum period (Review). Cochrane Database Syst Rev. 2017;(3):CD011761.

15. Błażewicz A, Makarewicz A, Korona-Glowniak I, Dolliver W, Kocjan R. Iodine in autism spectrum disorders. J Trace Elem Med Biol. 2016;34:32-7.

16. Melse-Boonstra A, Gowachirapant S, Jaiswal N, Winichagoon $\mathrm{P}$, Srinivasan K, Zimmermann MB. Iodine supplementation in pregnancy and its effect on child cognition. J Trace Elem Med Biol. 2012;26:134-6.

17. Iodine in pregnancy and lactation. WHO: Geneva, Switzerland; 2017.

18. Urinary iodine concentrations for determining iodine status deficiency in populations. Vitamin and Mineral Nutrition Information System. WHO: Geneva, Switzerland; 2013.

19. Gulaboglu M, Borekci B, Delibas I. Urine iodine levels in preeclamptic and normal pregnant women. Biol Trace Elem Res. 2010;136(3):249-57.

20. Borekci B, Gulaboglu M, Gul M. Iodine and magnesium levels in maternal and umbilical cord blood of preeclamptic and normal pregnant women. Biol Trace Elem Res. 2009;129:1-8.
21. Gulaboglu M, Borekci B, Halici Z. Placental tissue iodine level and blood magnesium concentration in pre-eclamptic and normal pregnancy. Int J Gynaecol Obstet. 2007;98:100-4.

22. Reische EC, Männistö T, Purdue-smithe A, Kannan K, Kim U, Suvanto E, et al. The joint role of Iodine status and thyroid function on risk for preeclampsia in finnish women : A population-based nested case-control study. Biol Trace Elem Res. 2021;199:2131-7 .

23. Iodine Global Network. Global Scorecard of Iodine Nutrition in 2017 in the general population and in pregnant women $(P W)$. National Center for Enviromentental Health: Zurich, Switzerland; 2017.

24. American College of Obstetricians and Gynecologists. Hypertension in Pregnancy. Report of the American College of Obstetricians and Gynecologists's Task Force of Hypertension in Pregnancy. Obstet Gynecol. 2013;122(5):1122-31.

25. Makhmudov AA, Caldwell KL. The Challenge of iodine deficiency disorder. A decade of CDC's Ensuring the Quality of Urinary Iodine Procedures Program. National Center for Enviromentental Health: Zurich, Switzerland; 2011:52-9.

26. Zimmer M, Sieroszewski P, Oszukowski P, Huras H, Fuchs T, Pawłosek A. Rekomendacje Polskiego Towarzystwa Ginekologów i Położników dotyczące suplementacji u kobiet ciężarnych. GiPP. 2020;5(4):170-181.

27. Gietka-Czernel M. Profilaktyka niedoboru jodu - Iodine prophylaxis. Post Nauk Med. 2015;XXVIII(12):839-45.

28. Springer D, Jiskra J, Limanova Z, Zima T, Springer D, Jiskra J, et al. Thyroid in pregnancy: From physiology to screening. Crit Rev Clin Lab Sci. 2017;54(2):102-16.

29. Nwabuobi C, Arlier S, Schatz F, Guzeloglu-Kayisli O. hCG: Biological Functions and Clinical Applications. Int J Mol Sci. 2017;18:2037.

30. Pessah-Pollack R, Eschler DC, Pozharny Z, Davies T. Apparent insufficiency of iodine supplementation in pregnancy. J Women's Health. 2014;23(1):51-6.

31. Bath SC, Furmidge-Owen VL, Redman CWG, Rayman MP. Gestational changes in iodine status in a cohort study of pregnant women from the United Kingdom: season as an effect modifier. Am J Clin Nutr. 2015;101:1180-7.

32. Sattar R, Ahmed E, Abbasi SQ. Thyroid hormones pattern in preeclampsia. Annals KEMU. 2018;24:863-6.

33. Muraleedharan N, Janardhanan JS. Thyroid hormone status in preeclampsia patients: A case - control study. J Res Med Sci. 2017;8: 68-73.

34. Khanam M, Ilias M. Study of thyroid hormonal status in preeclamptic patients. Med Today. 2013;25(02):63-6.

35. Gargari SS, Fateh R, Bakhshali-bakhtiari M, Saleh M, Mirzamoradi M, Bakhtiyari M. Maternal and neonatal outcomes and determinants of iodine deficiency in third trimester of pregnancy in an iodine sufficient area. BMC Pregnancy and Childbirth. 2020;20(174):1-9.

36. Yang J, Liu Y, Liu H, Zheng H, Li X, Zhu L, et al. Associations of maternal iodine status and thyroid function with adverse pregnancy outcomes in Henan Province of China. J Trace Elem Med Biol. 2018; 47:104-10.

37. Medici M, Korevaar TIM, Schalekamp-Timmermans S, Gaillard R, Rijke YB De, Visser WE, et al. Maternal early-pregnancy thyroid function is associated with subsequent hypertensive disorders of pregnancy: The generation R study. J Clin Endocrinol Metab. 2014; 99(12):e2591-8.

38. Lai H, Zhan Z, Liu H. Association between thyroid hormone parameters during early pregnancy and gestational hypertension: a prospective cohort study. J Intern Med. 2020;48(2):1-7.

39. Czerwińska E. Ocena spożycia jodu i sodu przez kobiety ciężarne. GiPP. 2018;3(1):10-5.

40. Szybiński Z. Sytuacja profilaktyki jodowej w Polsce w świetle ostatnich rekomendacji WHO dotyczących ograniczenia spożycia soli. Pediatr Endocrinol Diabetes Metab. 2009;15(2):103-7.

41. Zygmunt A, Adamczewski Z, Zygmunt A, Adamczewska K, Trofimiuk-Muldner M, Hubalewska-Dydejczyk A, et al. Ocena skuteczności profilaktyki jodowej w ciąży - analiza przeprowadzona w jednym z referencyjnych ośrodków. Endokrynol Pol. 2015; 66(5):404-11. 